\title{
Computational Evaluation of the Steady and Pulsed Jet Effects on the Performance of a Circulation Control Wing Section
}

\author{
Yi Liu, Lakshmi N. Sankar, Robert J. Englar, Krishan K. Ahuja, R. Gaeta
}

Georgia Institute of Technology, Atlanta, GA 30332-0150

\begin{abstract}
Circulation Control technology is a very effective way of achieving high lift forces required by aircraft during take-off and landing. This technology can also directly control the flow field over the wing. Compared to a conventional high-lift system, a Circulation Control Wing $(\mathrm{CCW})$ can generate comparable or higher lift forces during take-off/landing with fewer or no moving parts and much less complexity. In this work, an unsteady three-dimensional Navier-Stokes analysis procedure has been developed and applied to Circulation Control Wing configurations. The effects of 2-D steady jets and 2-D pulsed jets on the aerodynamic performance of CCW airfoils have been investigated. It is found that a steady jet can generate very high lift at zero angle of attack without stall, and that a small amount of blowing can eliminate vortex shedding at the trailing edge, a potential noise source. It is also found that a pulsed jet can achieve the same high lift as a steady jet at lower mass flow rates, especially at a high frequency, and that the Strouhal number has a more dominant effect on the pulsed jet performance than just the frequency or the free-stream velocity.
\end{abstract}




\section{INTRODUCTION}

During the past several decades, there has been a significant increase in air travel and a rapid growth in commercial aviation. At the same time, environmental regulations and restrictions on aircraft operations have become issues that affect and limit the growth of commercial aviation. In particular, the noise pollution from aircraft, especially around the airport, has become a major problem that needs to be solved. Reducing aircraft noise has become a priority for airlines, aircraft manufacturers, and NASA researchers.

Current generation large commercial aircraft are dependent on components that generate high levels of lift at low speeds during take-off or landing from existing runways. Conventional high-lift systems include flaps and slats, with the associated flap-edges and gaps that are significant noise sources. Furthermore, these high-lift systems also add to the weight of the aircraft, and are costly to build and maintain. An alternative to the conventional high-lift systems is the Circulation Control Wing (CCW) technology. This technology and its aerodynamic benefits have been extensively investigated over many years by Englar et al at Georgia Tech through experimental studies [1, 2]. A limited number of numerical analyses $[1,3,4]$ have also been done. Work has also been done on the acoustic characteristics of Circulation Control Wings [5]. These studies indicate that very high $C_{L}$ values (as high as 8.5 at $\alpha=0^{\circ}$ ) may be achieved with Circulation Control wings. Because many mechanical components associated with the high-lift system are no longer needed, the wings can be lighter and less expensive to build. Major airframe noise sources such as flap-edges, flapgaps, and trailing/leading edge flow-separation can all be eliminated with the use of CCW systems. 
Earlier designs of CCW configurations used airfoils with a large radius rounded trailing edge to maximize the lift production. However, these designs also produced very high drag [6]. Such high drag levels associated with a blunt, large radius trailing edge can be prohibitive under cruise conditions when Circulation Control is no longer necessary. To overcome this difficulty, an advanced CCW section, called a circulation hinged flap [1, 2], has been developed that replaces the traditional rounded trailing edge $\mathrm{CC}$ airfoil. This concept originally developed by Englar is shown in Figure 1. The upper surface of the CCW flap is a large-radius arc surface, but the lower surface of the flap is flat. The flap could be deflected from 0 degrees to 90 degrees. When an aircraft takes-off or lands, the flap is deflected as in a conventional high lift system, and Circulation Control is deployed. The large curvature of the upper surface produces a large jet turning angle, leading to high lift. When the aircraft is in cruise, the flap is retracted and a conventional sharp trailing edge shape results, greatly reducing the drag. This kind of flap does have some moving elements that increase the weight and complexity over the earlier CCW design. But overall, the hinged flap design still maintains most of the advantages of the Circulation Control, while greatly reducing the drag in cruising condition associated with the rounded trailing edge CCW design.

To understand and quantify the aeroacoustic characteristics and benefits of the Circulation Control Wing, Munro, Ahuja and Englar [7, 8, 9, 10] have recently conducted several acoustic experiments comparing the noise levels of a conventional high-lift system with that of an advanced $\mathrm{CC}$ wing at the same lift setting. The present Computational Fluid Dynamics (CFD) study [11] is intended to complement this work, and numerically investigate the aerodynamic characteristics and benefits associated with the CC airfoil. CFD studies 
such as the one presented here can also help in the design of future generation CCW configurations.

\section{SCOPE OF PRESENT WORK}

The present work is an extension of a previous work where 2-D studies of the effects of steady and pulsed jets on the CCW configuration shown in figure 1 were done [12]. The objective of this study is to isolate and quantify the effects of the parameters such as leading edge blowing, free-stream velocity, jet slot-height, and frequency, on the performance of 2-D steady and pulsed Circulation Control jets. The unsteady Navier-Stokes methodology used here has also been applied to study 3-D Circulation Control Wing and to model tangential blowing effects. These 3-D results have not been included here, and reader is referred to the Ph. D dissertation of the first author [11] for details.

\section{MATHEMATICAL AND NUMERICAL FORMULATION}

\section{Governing Equations}

In the present work, Reynolds-averaged Navier-Stokes equations were solved using an unsteady three-dimensional viscous flow solver. This solver can model flow fields over isolated wing-alone configurations. This solver has been validated for clean and iced wings by Kwon et al [13] and Bangalore et al [14]. As part of the first author's Ph. D work, modifications to this solver have been made to model Circulation Control jets. Both 3-D finite wings and 2-D airfoils may be simulated with the same solver. Two turbulence models have been used: the Baldwin-Lomax [15] algebraic model and Spalart and Allmaras [16] one 
equation model. In this work, all the calculations were done using the Baldwin-Lomax model. The effects of turbulence model are discussed in Ref. 11.

\section{Computational Grid}

Construction of a high-quality grid about the CCW airfoil is made difficult by the presence of the vertical jet slot. In this solver, the jet slot is treated as part of the airfoil surface as done by Shrewsbury [17, 18] and Williams and Franke[19]. A hyperbolic threedimensional $\mathrm{C}-\mathrm{H}$ grid generator is used in all the calculations. The three-dimensional grid is constructed from a series of two-dimensional C-grids with an H-type topology in the spanwise direction. The grid is clustered in the vicinity of the jet slot and the trailing edge to accurately capture the jet behavior over the airfoil surface.

The grid generation and the surface boundary condition routines are general enough so that one can easily vary the slot location, slot size, blowing velocity and the direction of blowing.

\section{Boundary Conditions}

In Circulation Control Wing studies, the driving parameter is the momentum coefficient, $\mathrm{C}_{\mu}$, defined as follows.

$$
C_{\mu}=\frac{\dot{m} V_{j e t}}{\frac{1}{2} \rho_{\infty} V_{\infty}^{2} S}
$$

Here, the jet mass flow rate is given by:

$$
\dot{m}=\rho_{j e t} V_{j e t} A_{j e t}
$$


Conventional airfoil boundary conditions are applied everywhere except at the jet slot exit. Non-reflection boundary conditions are applied at the outer boundaries of $\mathrm{C}$ grid. On the airfoil surface, adiabatic and no-slip boundary conditions are applied, and the normal derivative of the pressure is set to zero.

At the jet slot exit, the jet is assumed to be subsonic, and the following conditions are specified: total temperature of the jet, momentum coefficient $\mathrm{C}_{\mu}$ as a function of time, and the flow angle at the exit. In this simulation, the jet was tangential to the airfoil surface at the exit. All other parameters were computed using ideal gas law, and by equating the static pressure at the slot exit to the static pressure field over the airfoil, in the immediate vicinity of the jet slot.

\section{RESULTS AND DISCUSSION}

The CCW configuration studied in the present work is shown in Figure 2. The flap setting angle may be varied both in the experiments and the simulations. The studies presented here are all for the 30 degree flap setting. In both the experiments [1] and the present studies, the free-stream velocity was approximately $94.3 \mathrm{ft} / \mathrm{sec}$ at a dynamic pressure of $10 \mathrm{psf}$ and an ambient pressure of 14.2 psia. The free-stream density is 0.00225 slugs $/ \mathrm{ft}^{3}$. These conditions translate into a free-stream Mach number 0.0836 . The airfoil chord was 8 inch and the Reynolds number was 395,000. 


\section{Validation Studies}

Prior to its use in studying CCW configurations, the Navier-Stokes solver was validated by modeling the viscous subsonic flow over a small aspect-ratio wing made of NACA 0012 airfoil sections [12], and the results were in good agreement with the experimental measurement of Bragg and Spring [20]. These validation studies have been previously documented in Ref. 11 and 12, and are not reproduced here.

Figure 3 shows the variation of lift coefficient with respect to $C_{\mu}$ at a fixed angle of attack ( $\alpha=0$ degree) for the CCW configuration with a 30-degree flap. Excellent agreement with measured data from the experiments by Englar [1] is evident. It is seen that very high lift can be achieved by Circulation Control technology with a relatively low $C_{\mu}$. A lift coefficient as high as 4 can be obtained at a $\mathrm{C}_{\mu}$ value of 0.33 , and the lift augmentation $\Delta \mathrm{C}_{\mid} / \Delta \mathrm{C}_{\mu}$ is greater than 10 for this 30 -degree flap configuration.

Figure 4 shows the computed $C_{1}$ variation with the angle of attack, for a number of $\mathrm{C}_{\mu}$ values, along with measured data. It is found that the lift coefficient increases linearly with angle of attack until stall, just as it does for conventional sharp trailing edge airfoils. However, the increase of lift with angle of attack breaks down at high enough angles. This is due to leading edge static stall, and is much like that experienced with a conventional airfoil, but occurs higher $\mathrm{C}_{l, \max }$ values, thanks to the beneficial effects of Circulation Control. The calculations also correctly reproduce the decrease in the stall angle observed in the experiments at high momentum coefficients. Unlike conventional airfoils that experience stall due to the progressive growth of trailing edge separation, CCW configurations stall due to leading edge separation. Figure 5 shows typical streamlines around the $\mathrm{CC}$ airfoil at an angle of attack of 6 degrees, and $C_{\mu}=0.1657$ at a typical instance in time. In this case, a 
leading edge separation bubble forms, that spreads over the entire upper surface resulting in a loss of lift. However, the flow is still attached over the trailing edge because of the strong Coanda effect.

\section{Leading Edge Blowing}

Functioning like a slat, leading edge blowing is an effective way of alleviating leading edge stall and for achieving the desired performance at high angles of attack. To understand the effects of leading edge blowing, a dual-slot CC airfoil was designed, and simulations of both leading edge (LE) and trailing edge (TE) blowing were done. Figure 6 shows lift coefficient variations with angle of attack for three different combinations of LE and TE blowing. In the first case, there is only a TE blowing with $C_{\mu}=0.08$, and it is seen that the stall angle is very small, at approximately 5 degrees. If a small amount of LE blowing is used $\left(C_{\mu}=0.04\right)$, while keeping the TE blowing at $C_{\mu}=0.08$ as before, the stall angle is greatly increased from 5 degrees to 12 degrees. If even higher levels of LE blowing is used, e.g. a LE blowing with $C_{\mu}=0.08$ and a TE blowing with $C_{\mu}=0.04$, the stall angle is increased to more than 20 degrees, but the total lift is decreased at the same angle of attack compared to the previous case even when the total momentum coefficients $\left(\mathrm{C}_{\mu, \mathrm{LE}}+\mathrm{C}_{\mu, \mathrm{TE}}\right)$ of the both cases are the same, equal to 0.12 here.

In conclusion, the leading edge blowing is seen to increase the stall angle, replacing the slat, while the trailing edge blowing is effective in producing high levels of lift. Leading edge blowing can also reduce the large nose down pitch moment associated with high lift and the suction pressure peak in the vicinity of the slot. In general, operating at high angles of attack is not necessary for $\mathrm{CC}$ airfoils since high lift can be readily achieved with low 
angles of attack and a moderate amount of blowing. But in situations where the CCW configuration must operate at high angles of attack, a combination of leading edge and trailing edge blowing may be necessary to achieve the best performance.

\section{Effects of Free-stream Velocity on Lift Production}

As a follow up to previous studies [12], numerical simulations have also been done where the free-stream velocities (and the Reynolds number) were systematically varied. The purpose of theses studies was to determine and isolate how free-steam velocities and the Reynolds number affect the beneficial effects of Circulation Control at a fixed momentum coefficient.

In this case, the jet momentum coefficient, $C_{\mu}$, is fixed at 0.1657 , and the jet slot height is also fixed at 0.015 inch. The free-stream velocities vary from 0.5 to 1.8 times the experimental free-stream velocity, equal to $94.3 \mathrm{ft} / \mathrm{sec}$ as stated earlier. The jet velocity also varies with the free-stream velocity to maintain a constant $C_{\mu}$. As shown in Figures 7 and 8 , for a given momentum coefficient, the lift and drag coefficients are not significantly affected by the variation of the free-stream velocity except at very low free-stream velocities. At very low free-stream velocities, degradation of lift and the generation of high drag are seen. This is because the jet velocity is too low to generate a sufficiently strong Coanda effect that eliminates trailing edge separation and vortex shedding. At sufficiently high free-stream velocities, the performance of CC airfoils is independent of the free-stream velocity and the Reynolds number under the fixed $\mathrm{C}_{\mu}$ and fixed jet slot height conditions. Thus the momentum coefficient is an appropriate driving parameter for CC blowing if the jet slotheight is fixed. 


\section{Effects of Jet Slot Height}

According to recent acoustic measurements [7, 8], the jet slot height has a strong effect on the noise produced by the CC airfoil. These studies indicate that a larger jet slot will reduce the noise at the same momentum coefficient compared to a smaller slot. To investigate the effect of jet slot heights on the aerodynamic characteristics of CCW sections, simulations at several slot heights (varied from 0.006 inch to 0.018 inch) have been done, at a fixed low $C_{\mu}\left(C_{\mu}=0.04\right)$ and a fixed high $C_{\mu}\left(C_{\mu}=0.1657\right)$ value, and at a constant freestream velocity of $94.3 \mathrm{ft} / \mathrm{sec}$.

From Figure 9, it is seen that a higher lift coefficient can be achieved with a smaller slot height even for the same momentum coefficient, and that the lift coefficient is decreased by $20 \%$ as the slot height is increased from 0.006 inch to 0.018 inch. A similar behavior is seen for the drag coefficient as shown in Figure 10. The L/D characteristics of the airfoil, which is computed here as $C_{/} /\left(C_{d}+C_{\mu}\right)$ by adding $C_{\mu}$ to the drag coefficient in order to consider the rate of change of momentum associated by the jet flow, does not vary much with the change of the jet slot height. As shown in Figure 11, when the slot height is increased, the efficiency decreases approximately by $7.6 \%$ for $C_{\mu}=0.1657$ case, and increases by about $5.3 \%$ for the $C_{\mu}=0.04$ case. However, as shown in Figure 12, the jet mass flow rate increases by $\sim 60 \%$ when the slot height is increased from 0.006 inch to 0.018 inch, due to the larger jet slot area.

As it is always preferable to obtain higher lift with as low a mass flow rate as possible, a thin jet is aerodynamically more beneficial than a thick jet. However, the large stagnation pressure losses associated with small orifices or slots means that a higher 
stagnation pressure is required to generate a jet issuing through a smaller slot than through a larger slot at the same momentum coefficient. The higher power consumption of compressors needed to produce the required high stagnation pressures can negate the beneficial effects of Circulation Control for very thin jets.

In summary, a smaller jet slot height is preferred from an aerodynamic design perspective. However, as mentioned above, a larger jet slot height is preferred from an aeroacoustic perspective. Thus, an optimum choice must be made for the jet slot height from aerodynamic, acoustic, and compressor power consumption considerations.

\section{Pulsed Jet Effects}

In earlier work [12], it has been shown that the pulsed jet with square-wave form is more efficient than the traditional sinusoidal form and that the square-wave form pulsed jet can generate the same lift of the steady jet at a much lower mass flow rate. In this work, we describe the studies done to isolate the effects of free-stream velocity, frequency, and chord length on pulsed jet behavior.

Figures 13 and 14 show the variation of the time-averaged incremental lift coefficient $\Delta C_{\text {l }}$ over and above the base-line unblown configuration at three frequencies, $40 \mathrm{~Hz}, 120 \mathrm{~Hz}$ and $400 \mathrm{~Hz}$. Figure 13 shows the variation with the average momentum coefficient, ${ }_{0}$ and Figure 14 shows the variation with the average mass flow rate.

At first glance, Figure 13 and Figure 14 will appear to show opposite trends. Figure 14 appears to favor high frequencies - i.e. $\Delta C_{\mid}$increases as frequency increases, and pulsed jet produces a higher $\Delta \mathrm{C}_{\mathrm{I}}$ than a steady jet. This appears to be consistent with experiments

[21]. However, Figure 13 appears to show the opposite trend - steady jet appears to be 
always more efficient than a pulsed jet, and produces a large $\Delta C_{\text {| }}$. To resolve this "apparent" inconsistency between Figure 13 and 14, four points A, B, C, D are shown in Figure 13. These points are all at the same mass flow rate of $0.00088 \mathrm{slug} / \mathrm{sec}$. It is seen that point $A$ is above point $\mathrm{B}$. That is, a steady jet is indeed able to produce a higher $\Delta \mathrm{C}_{\text {| }}$ than a low frequency $40 \mathrm{~Hz}$ jet. This is because the flow separates over a period of time before a new cycle of blowing begins, destroying the lift generation. However, points C and D (120 and $400 \mathrm{~Hz}$ jets) are higher than point A. In these cases, bound circulation over the airfoil has not been fully shed into the wake before a new cycle begins. The time-averaged lift at the same specified averaged mass flow rate is thus higher compared to a steady jet. This is consistent with Figure 14.

It has also been found that high frequencies have the beneficial effect of decreasing the time-averaged mass flow rate of the pulsed jet [12]. For example, as shown in Figure 15, when the frequency is equal to $400 \mathrm{~Hz}$, the pulsed jet requires only $73 \%$ of the steady jet mass flow rate while it can achieve $95 \%$ of the average lift achieved with a steady blowing. Examination of the flow field over an entire cycle indicates that it takes some time after the jet has been turned off before all the beneficial circulation attributable to the Coanda effect is completely lost. If a new blowing cycle could begin before this occurs, the circulation will almost instantaneously reestablish itself. At high enough frequencies, as a consequence, the pulsed jet will have all the benefits of the steady jet at considerably lower mass flow rates.

For aerodynamic and acoustic studies, the frequency is usually expressed as a nondimensional quantity called the Strouhal number. Simulations has been done to calculate 
the average lift generated by the pulsed jet at fixed Strouhal numbers, which is defined as follows:

$$
S t=\frac{f L_{r e f}}{V_{\infty}}
$$

In the present study, for the baseline case, the $L_{\text {ref }}$ is 8 inches, and the $V_{\infty}$ is equal to 94.3 $\mathrm{ft} / \mathrm{sec}$. For a $200 \mathrm{~Hz}$ pulsed jet, the Strouhal number is equal to 1.41 .

From the above equation, besides the frequency, there are other two parameters that could affect the Strouhal number- the free-stream velocity $V_{\infty}$ and $L_{\text {ref }}$ (Chord of the $C C$ airfoil). To isolate these effects, as shown in Tables 1-3, three cases have been studied. In the first case (Table 1) the free-stream velocity and the chord of the CC airfoil are fixed, and the Strouhal number varies with the frequency. In the second case, as shown in Table 2, the Strouhal number is fixed at 1.41 and the chord of the CC airfoil is also fixed. The frequency varies with the free-stream velocity to achieve the same Strouhal number. In the third case, as shown in Table 3, the Strouhal number is fixed at 1.41 and the free-stream velocity is also fixed, while the frequency varies along with the chord of the $\mathrm{CC}$ airfoil. The Mach number and Reynolds number are also functions of the free-stream velocity and the airfoil chord, and were changed appropriately. The time-averaged momentum coefficient, $C_{\mu, 0}$, is fixed at 0.04 in these studies. Figure 16 shows the lift coefficient variation with the frequency for these three cases.

From tables 2 and 3, it is seen that the computed time-averaged lift coefficient varies less than $2 \%$ when the Strouhal number is fixed, and the chord and/or the free-stream velocity is varied. Table 2 indicates that the same $C_{\mid}$can be obtained at a much lower frequency with a smaller free-stream velocity as long as the Strouhal number is fixed. Table 
3 shows that for a larger configuration, the same $C_{\mid}$can be obtained at a lower frequency provided the Strouhal number is fixed. Table 1, on the other hand, shows that varying the frequency and Strouhal number while holding the other variables fixed can lead to a $12 \%$ variation in $\mathrm{C}_{\mid}$. Thus, it is concluded the Strouhal number has a more dominant effect on the average lift coefficient of the pulsed jet than just the frequency.

\section{CONCLUDING REMARKS}

Navier-Stokes simulations are necessary for modeling flow over the CCW configurations due to the complexity of the flow field and the strong viscous effects. The results indicate that this approach is an efficient and accurate way of modeling CCW flows with steady and pulsed jets.

The Circulation Control Technology is a useful way of achieving very high lift at even zero angle of attack. It can also eliminate the vortex shedding in the trailing edge region, a potential noise source. The lift coefficient of the $\mathrm{CC}$ airfoil is also increased with angle of the attack as with the conventional sharp trailing edge airfoil. However, the stall angle of the CC airfoil decreases rapidly with an increase in the blowing momentum coefficient. This stall phenomenon occurs in the leading edge region, and may be suppressed by leading edge blowing. In practice, because high $\mathrm{C}_{\mathrm{L}}$ values are achievable at low angles of attack, it may seldom be necessary to operate $\mathrm{CC}$ wings at high angles of attack. However, because there is always a large nose down pitch moment for the CC airfoil, leading edge blowing may be necessary to reduce this pitch moment at high $\mathrm{C}_{\mu}$ values, even at zero angle of attack. 
At a fixed momentum coefficient, the performance of the $\mathrm{CC}$ airfoil does not vary significantly with free-stream velocity and the Reynolds number. However, at a fixed $C_{\mu}$, the lift coefficient is influenced by the jet slot height. A thin jet from a smaller slot is preferred since it requires much less mass flow, and has the same efficiency in generating the required $C_{\mid}$values as a thick jet. From a practical perspective, a much higher plenum pressure may be needed to generate thin jets for a given $C_{\mu}$. This may increase the power requirements of compressors that provide the high-pressure air.

A square wave shape pulsed jet configuration gives larger increments in lift over the baseline unblown configuration, when compared to the steady jet at the same timeaveraged mass flow rate. Pulsed jet performance is improved at higher frequencies due to the fact that the airfoil has not fully shed the bound circulation into the wake before a new pulse cycle begins.

The Strouhal number, has a more dominant effect on the performance of the pulsed jet than just the frequency. Thus, the same performance of a pulsed jet could be obtained at lower frequencies for a larger configuration or at smaller free-stream velocities provided the Strouhal number is kept the same.

\section{ACKNOWLEDGEMENT}

This work was supported by NASA Langley Research Center under the Breakthrough Innovative Technology Program, Grant-NAG1-2146. 


\section{REFERENCES}

1. Englar, Robert J., Smith, Marilyn J., Kelley, Sean M. and Rover, Richard C. III., "Application of Circulation Control to Advanced Subsonic Transport Aircraft, Part I: Airfoil Development," Journal of Aircraft, Vol.31 No.5, pp. 1160-1168, Sep. 1994.

2. Englar, Robert J., Smith, Marilyn J., Kelley, Sean M. and Rover, Richard C. III., "Application of Circulation Control to Advanced Subsonic Transport Aircraft, Part II: Transport Application," Journal of Aircraft, Vol.31, No.5, pp. 1169-1177, Sep. 1994.

3. Shrewsbury, G. D. and Sankar, L. N., "Dynamic stall of an oscillating circulation control airfoil," International Symposium on Nonsteady Fluid Dynamics, Toronto, Canada, June 4-7, 1990, Proceedings. New York, American Society of Mechanical Engineers, pp. 15-22, 1990.

4. Shrewsbury, G. D. and Sankar, L. N., "Dynamic Stall of Circulation Control Airfoils," AIAA Paper 90-0573, January 1990.

5. Salikuddin, M., Brown, W. H. and Ahuja, K. K., "Noise From a Circulation Control Wing with Upper Surface Blowing," Journal of Aircraft, Vol.24, pp55-64, Jan. 1987.

6. Englar, R. J. and Huson, G. G., "Development of Advanced Circulation Control Wing High Lift Airfoils," AIAA paper 83-1847, presented at AIAA Applied Aerodynamics Conference, July, 1983.

7. Munro, S., Ahuja, K., and Englar, R., "Noise Reduction Through Circulation Control Technology," AIAA Paper 2001-0666, Jan. 2001. 
8. Munro, S. and Ahuja, K. K., "Aeroacoustics of a High Aspect-Ratio Jet," AIAA paper 20033323, 2003, presented at the $9^{\text {th }}$ AIAA/CEAS Aeroacoustics Conference and Exhibit, Hilton Head, South Carolina, 12-14 May 2003.

9. Munro, S. and Ahuja, K. K., "Fluid Dynamics of a High Aspect-Ratio Jet," AIAA paper 20033129, 2003, presented at the $9^{\text {th }}$ AIAA/CEAS Aeroacoustics Conference and Exhibit, Hilton Head, South Carolina, 12-14 May 2003.

10. Munro, S. and Ahuja, K. K., "Development of a Prediction Scheme for Noise of HighAspect Ratio Jets," AIAA paper 2003-3255, 2003, presented at the $9^{\text {th }}$ AIAA/CEAS Aeroacoustics Conference and Exhibit, Hilton Head, South Carolina, 12-14 May 2003.

11. Liu, Y., "Numerical Simulations of the Aerodynamic Characteristics of Circulation Control Wing Sections," Ph.D Thesis, Georgia Institute of Technology, 2003.

12. Liu, Y., Sankar, L. N., Englar, R. J. and Ahuja, K. K., "Numerical Simulations of the Steady and Unsteady Aerodynamic Characteristics of a Circulation Control Wing Airfoil," AIAA paper 2001-0704, January 2001.

13.Kwon, J. and Sankar, L.N., "Numerical Study of the Effects of Icing on Finite Wing Aerodynamics," AIAA Paper 90-0757.

14.Bangalore, A., Phaengsook, N. and Sankar, L. N., "Application of a Third Order Upwind Scheme to Viscous Flow over Clean and Iced Wings," AIAA Paper 94-0485.

15.Baldwin, B. S., and Lomax, H., "Thin Layer Approximation and Algebraic Model for Separated Turbulent Flows," AIAA Paper 78-257, Jan. 1978.

16. Spalart, P. R., and Allmaras, S. R., "A One-Equation Turbulence Model for Aerodynamic Flows," AIAA Paper 92-0439, Jan. 1992. 
17. Shrewsbury, G. D., "Numerical Evaluation of Circulation Control Airfoil Performance Using Navier-Stokes Methods," AIAA paper 86-0286, January 1986.

18. Shrewsbury, G. D., "Numerical Study of a Research Circulation Control Airfoil Using Navier-Stokes Methods," Journal of Aircraft, Vol. 26, No. 1, pp.29-34, 1989.

19. Williams, S. L. and Franke, M. E., "Navier-Stokes Methods to Predict Circulation Control Airfoil Performance," Journal of Aircraft, Vol. 29, No.2, pp.243-249, March-April 1992.

20.Bragg, M. B., and Spring, S. A., "An Experimental Study of the Flow Field about an Airfoil with Glaze Ice," Presented at the AIAA $25^{\text {th }}$ Aerospace Science Meeting, Reno, Nevada, AIAA paper 87-0100, Jan 12-15, 1987.

21. Oyler, T.E., and W.E. Palmer, "Exploratory Investigation of Pulse Blowing for Boundary Layer Control," North American Rockwell Report NR72H-12, Jan. 1972. 


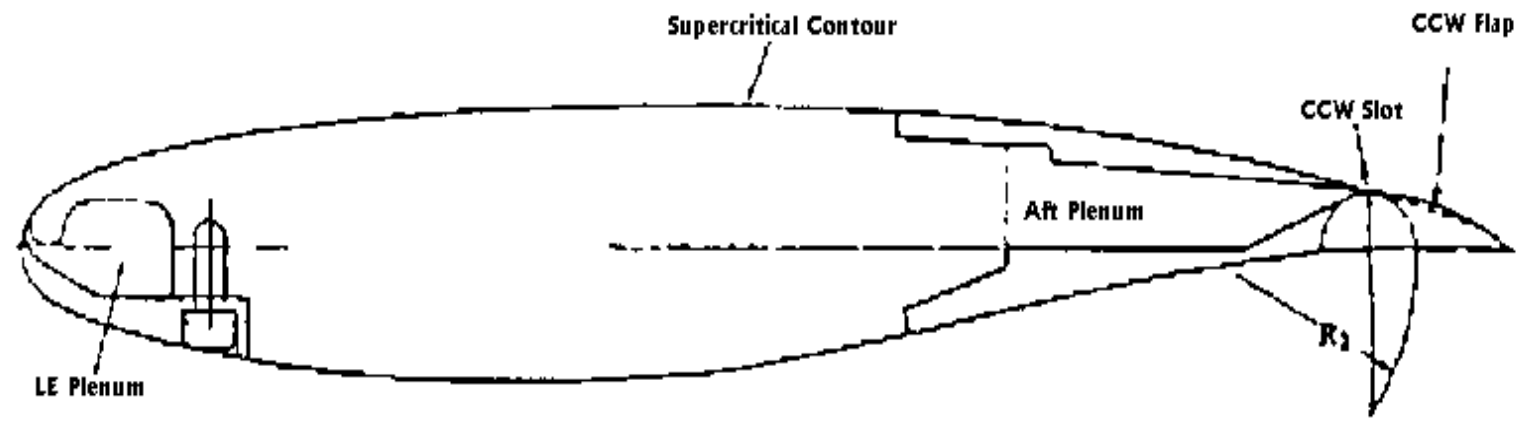

Figure 1 Dual Radius CCW Airfoil with LE Blowing [2]

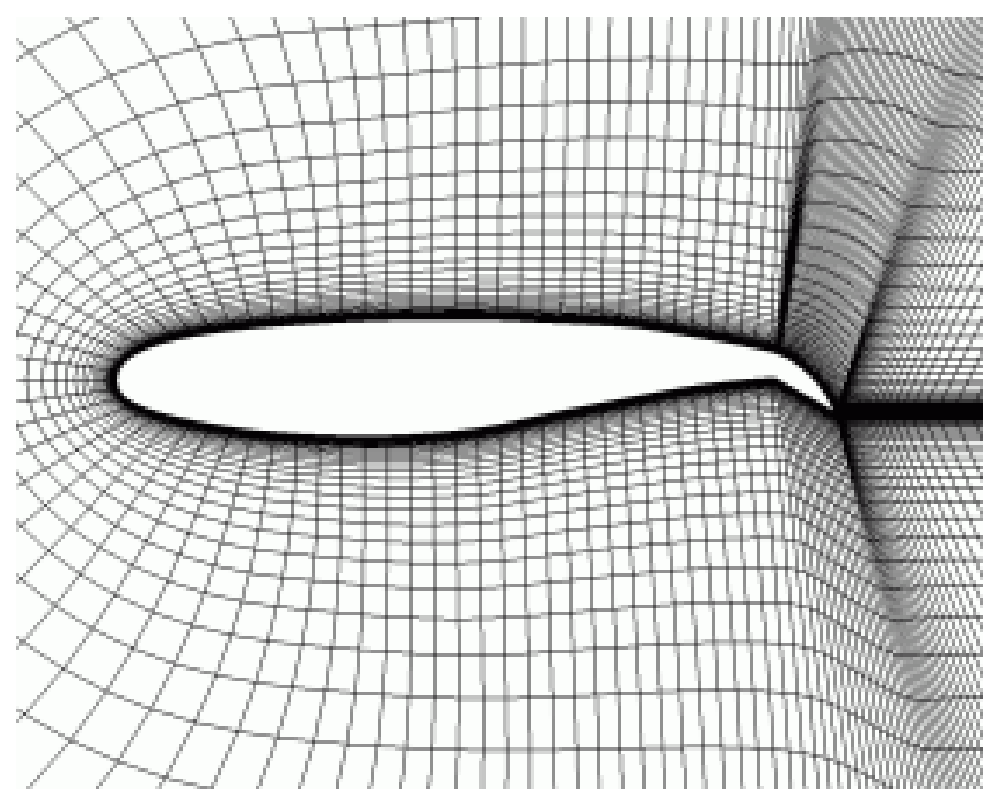

Figure 2 Body-fitted C Grid near the CC Airfoil Surface. 


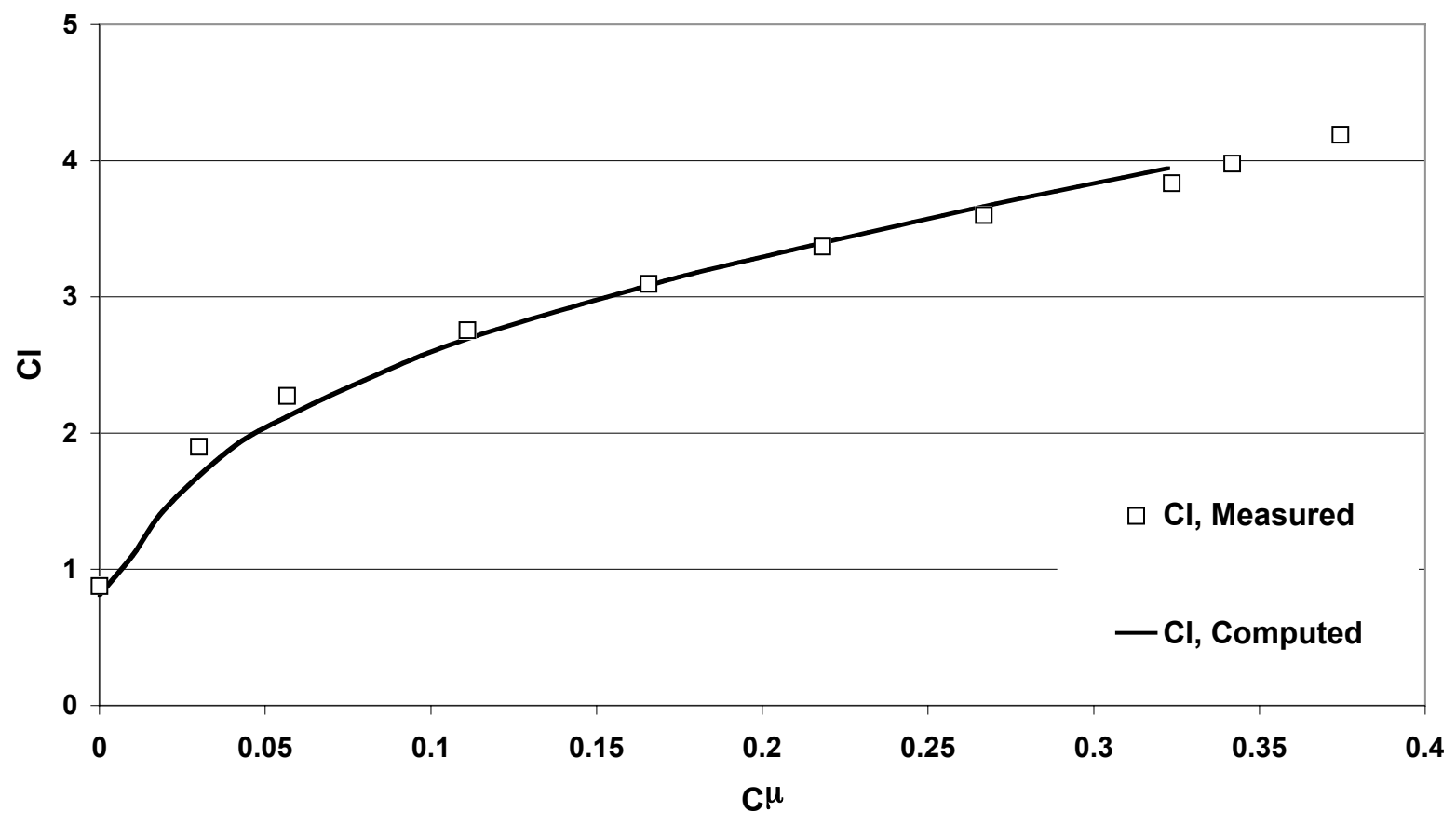

Figure 3 Variation of the Lift Coefficient with Momentum Coefficients at $\alpha=0^{\circ}$

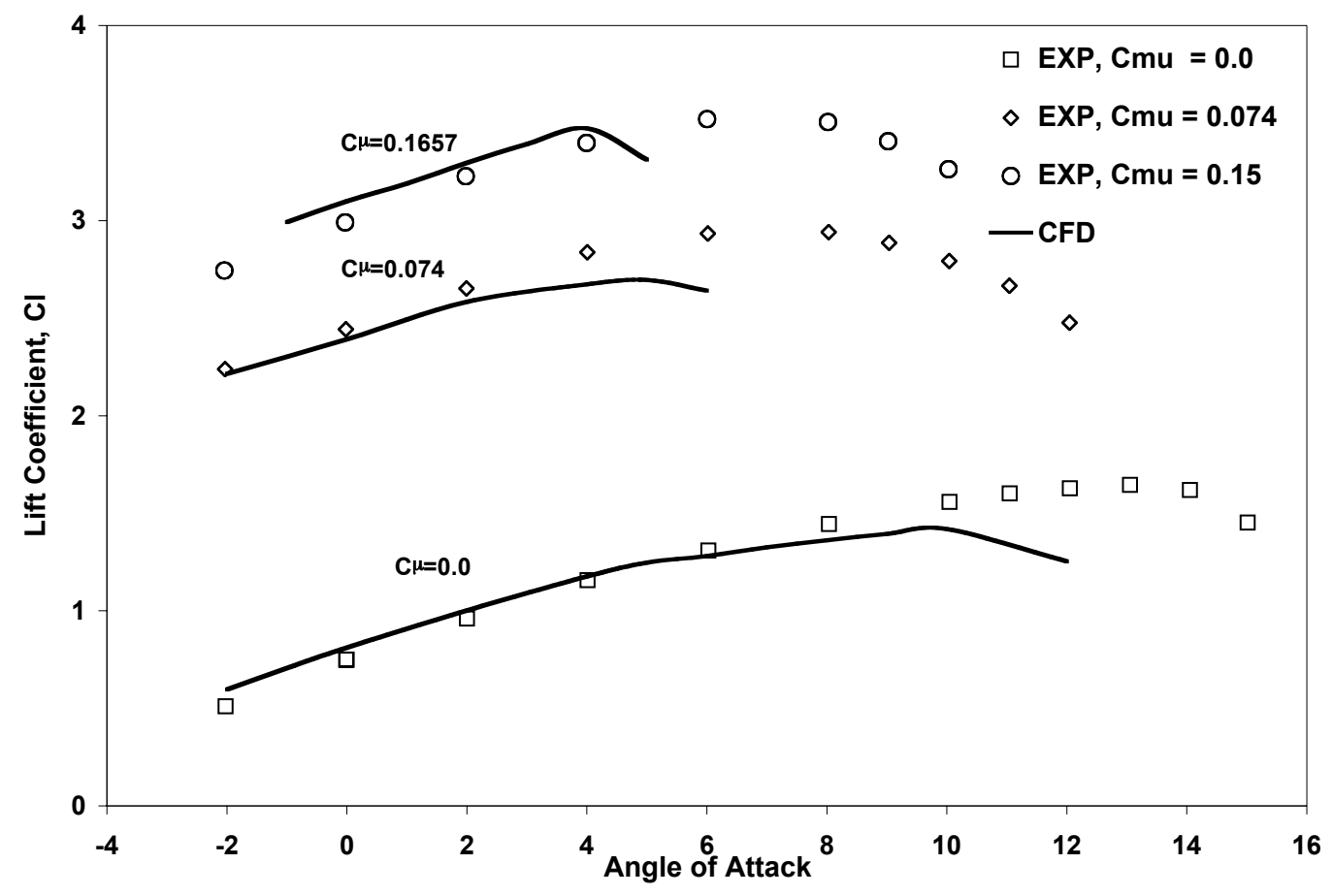

Figure 4 Variation of the Lift Coefficient with Angle of Attack 


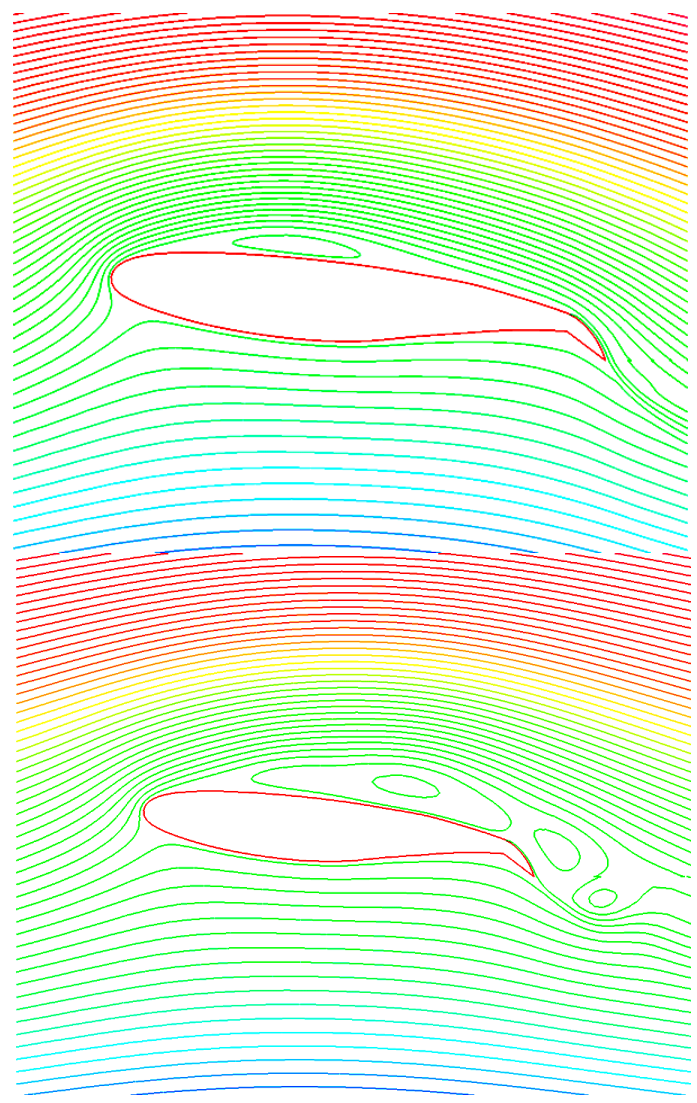

Figure 5 Streamlines over the CC airfoil at Two Instantaneous Time Levels $\left(C_{\mu}=0.1657\right.$, Angle of Attack $\left.=6^{0}\right)$

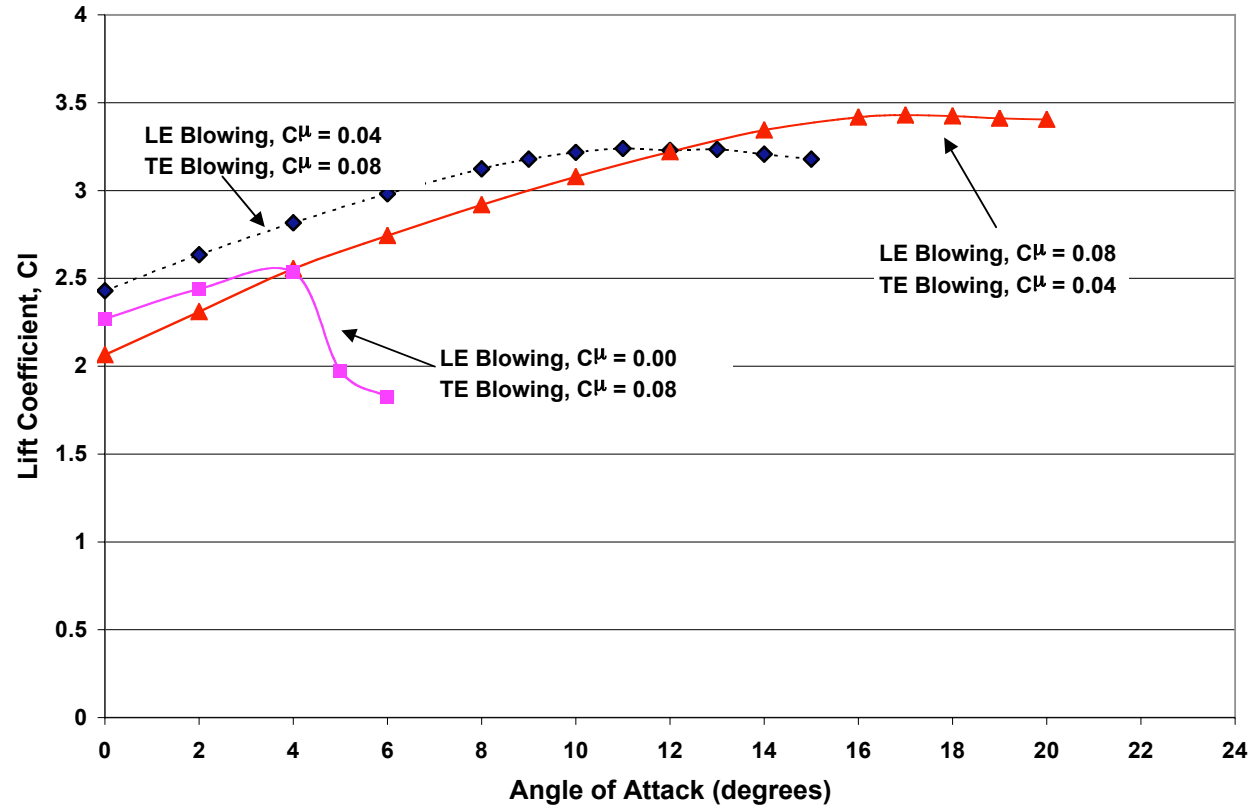

Figure 6 Lift Coefficient vs. the Angle of Attack for the Leading Edge Blowing Case 


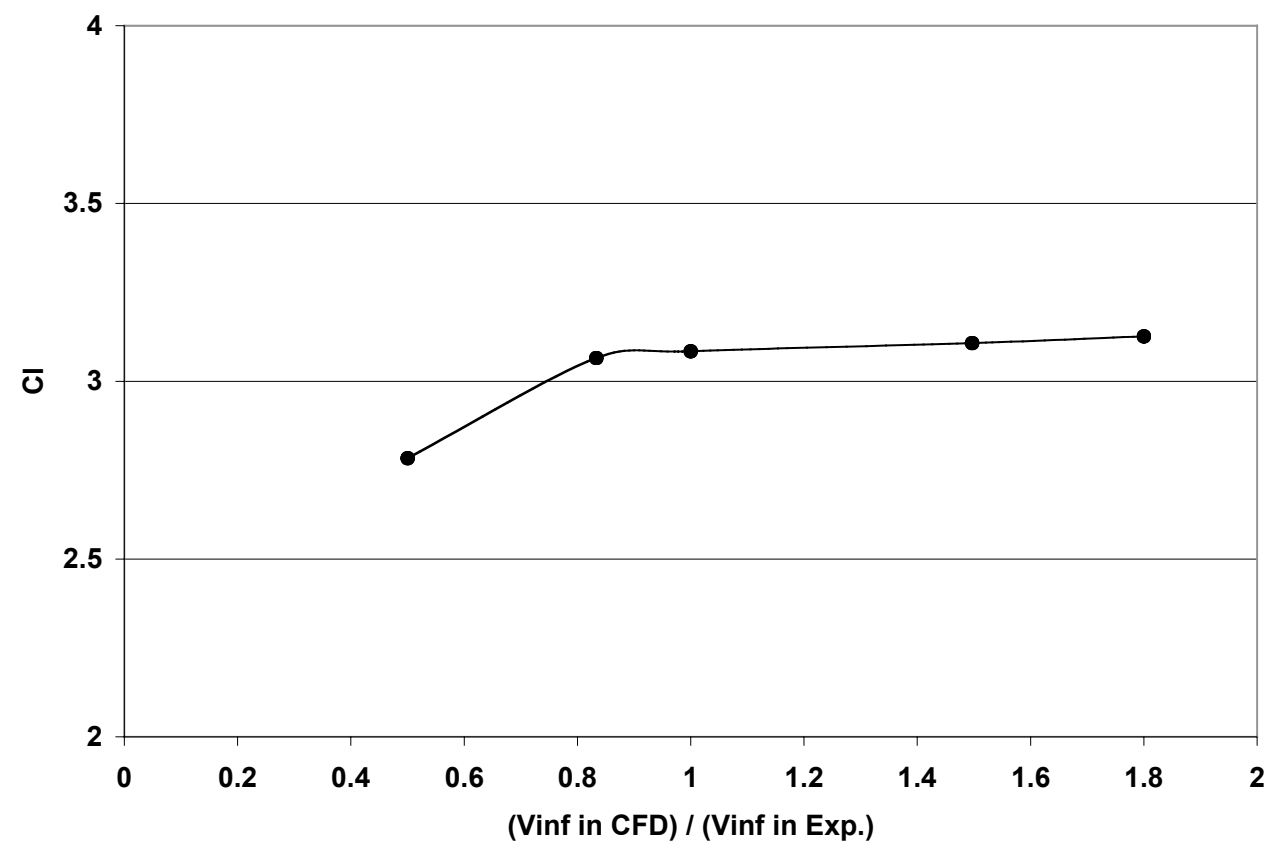

Figure 7 Lift Coefficient vs. Free-stream Velocity $\left(C_{\mu}=0.1657, h=0.015\right.$ inch and $\left.V_{\infty, \exp }=94.3 \mathrm{ft} / \mathrm{sec}\right)$

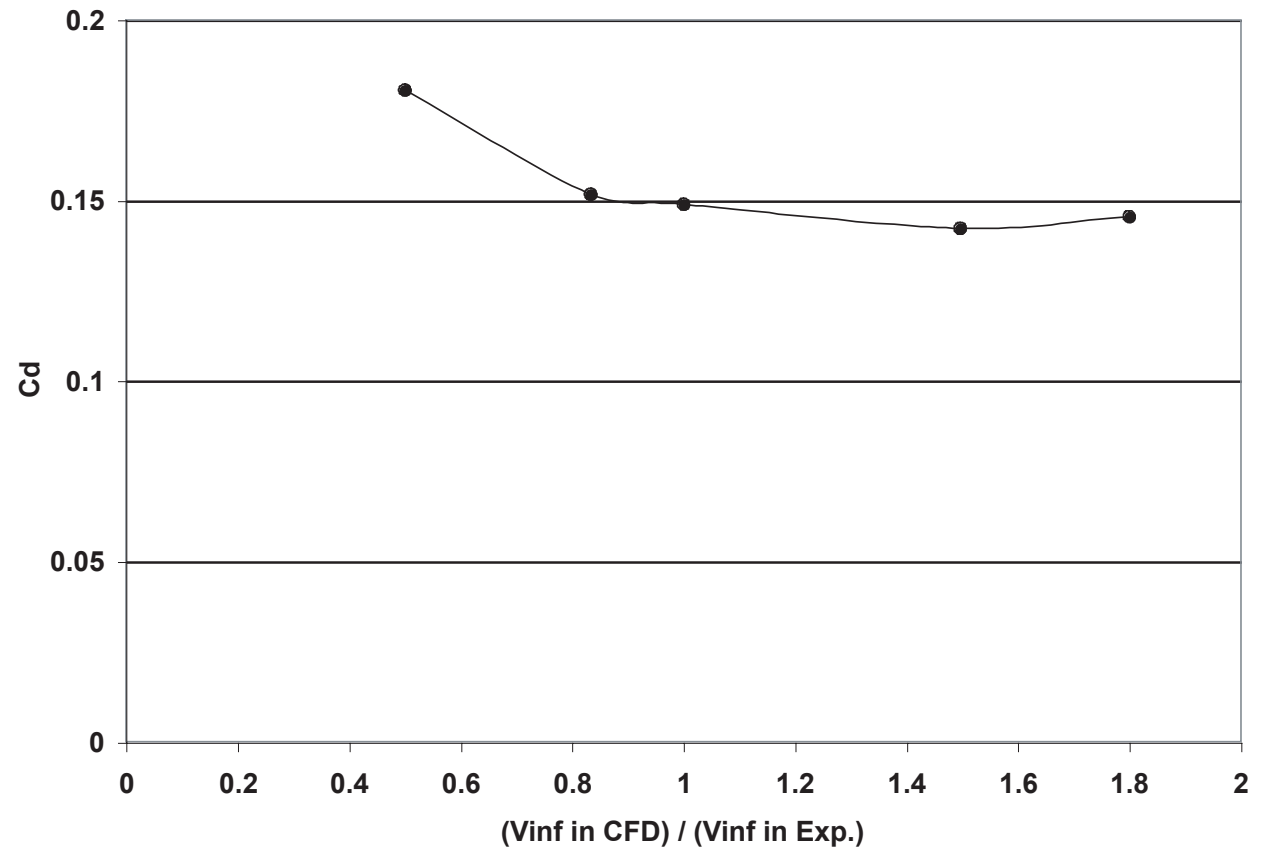

Figure 8 Drag Coefficient vs. Free-stream Velocity $\left(C_{\mu}=0.1657, h=0.015\right.$ inch and $\left.V_{\infty, \text { exp }}=94.3 \mathrm{ft} / \mathrm{sec}\right)$ 


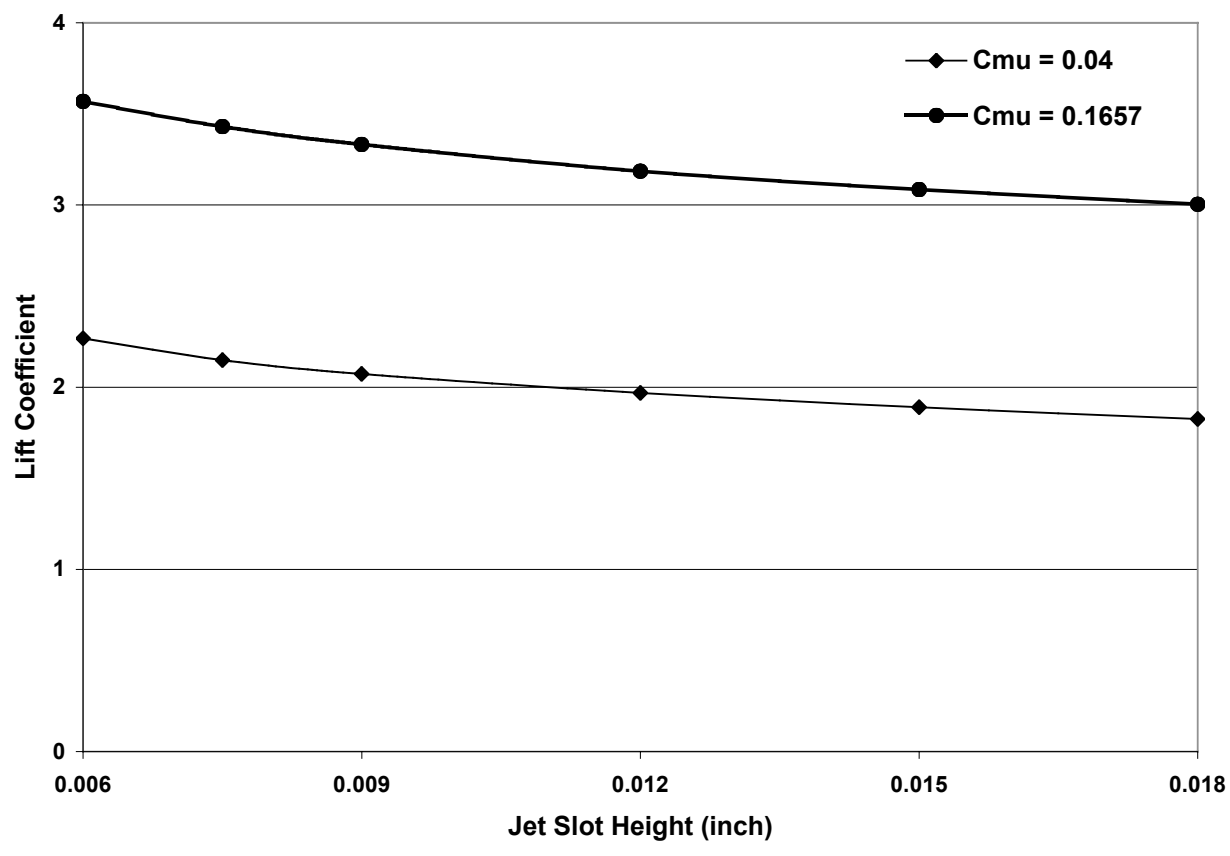

Figure 9 Lift Coefficient vs. Jet Slot Height $\left(\mathrm{V}_{\infty}=94.3 \mathrm{ft} / \mathrm{sec}\right)$

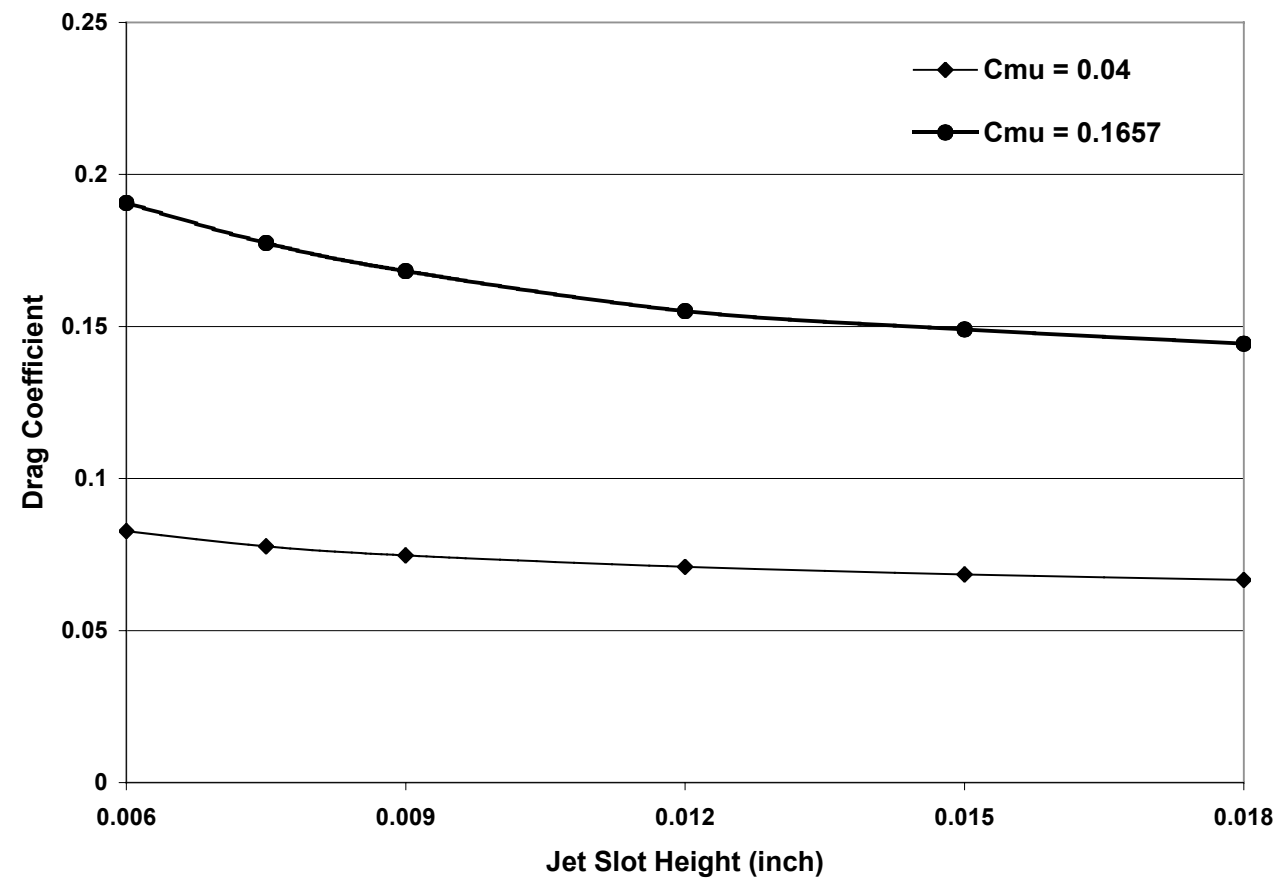

Figure 10 Drag Coefficient vs. Jet Slot Height

$\left(V_{\infty}=94.3 \mathrm{ft} / \mathrm{sec}\right)$ 


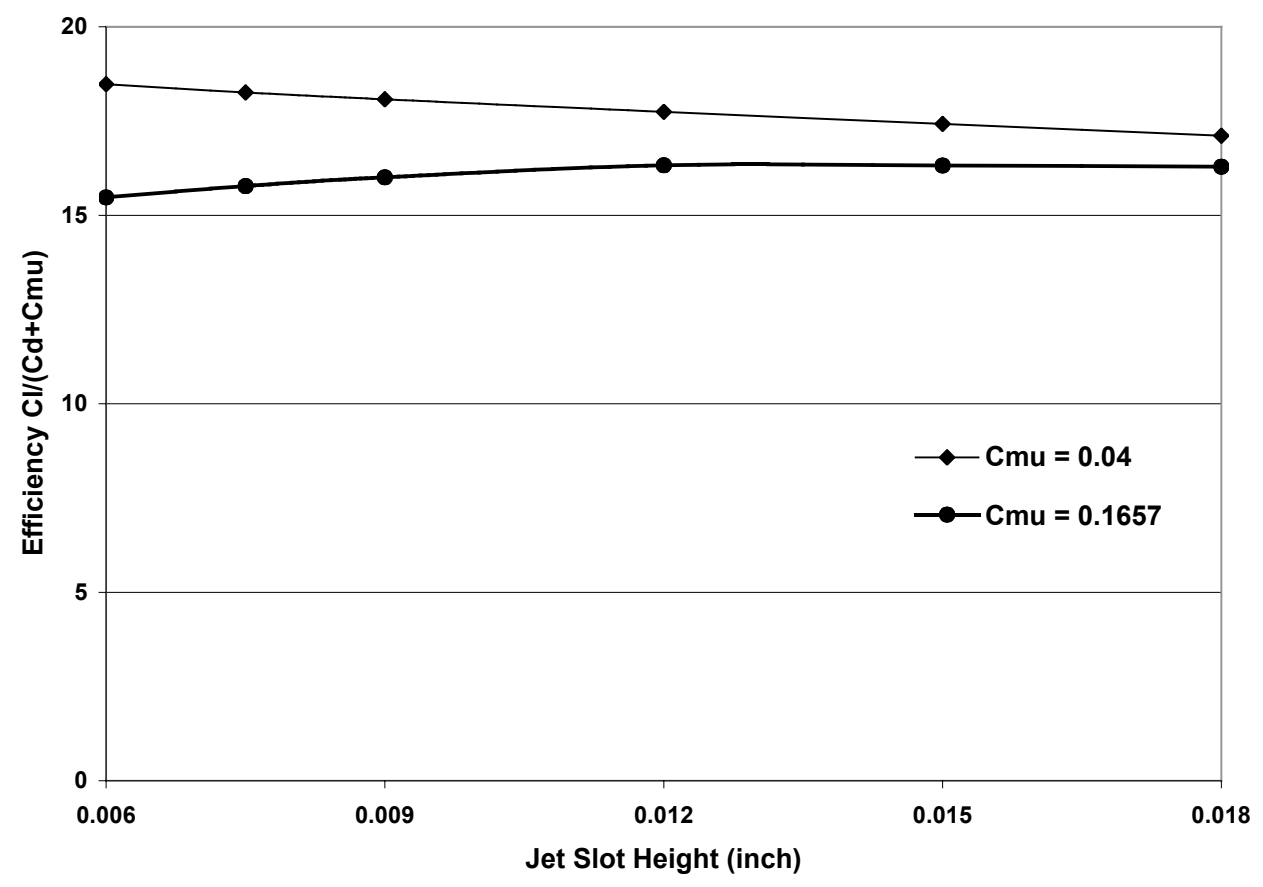

Figure 11 Variations of the L/D characteristics of with Jet Slot Height $\left(V_{\infty}=94.3 \mathrm{ft} / \mathrm{sec}\right)$

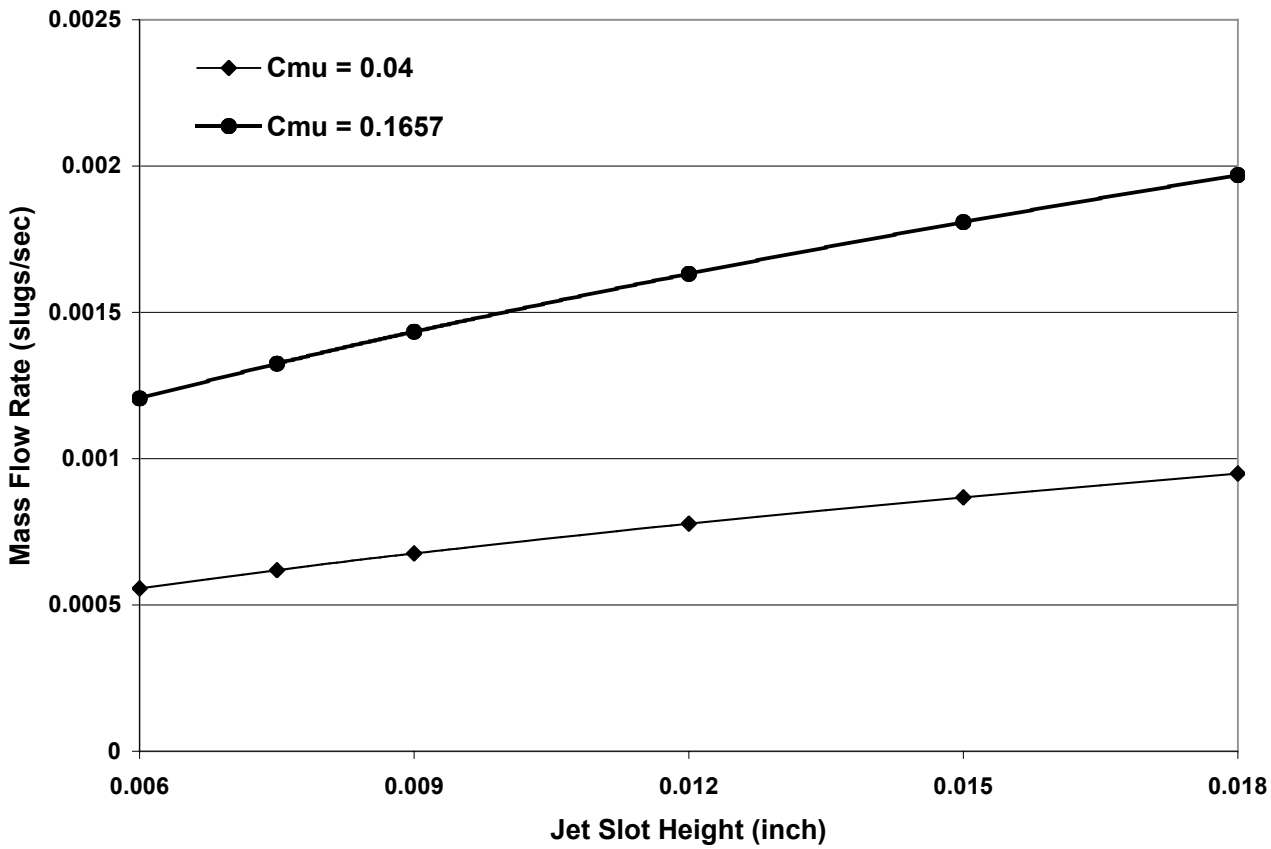

Figure 12 Mass Flow Rate Requirements of the Jet per foot of span vs. Jet Slot Height $\left(\mathrm{V}_{\infty}=94.3 \mathrm{ft} / \mathrm{sec}\right)$ 


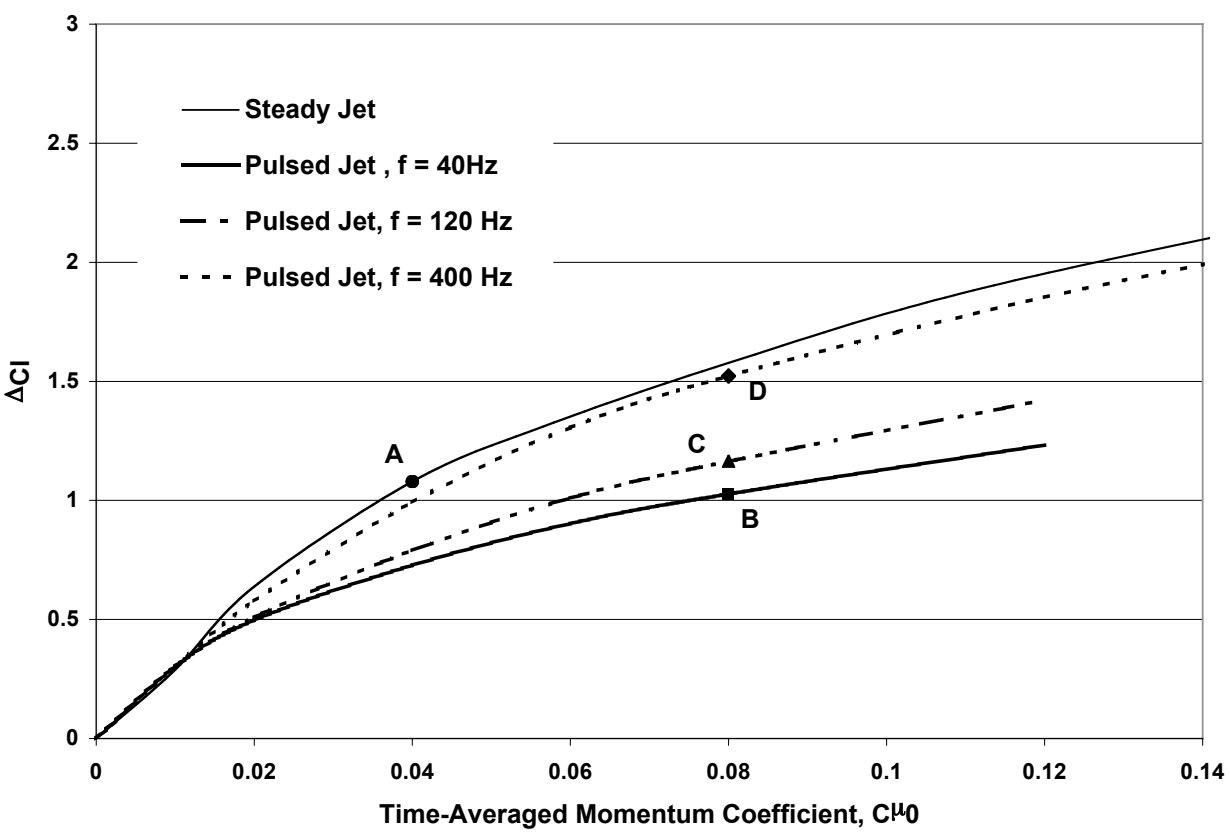

Figure 13 Incremental Lift vs. the Time-averaged Momentum Coefficient

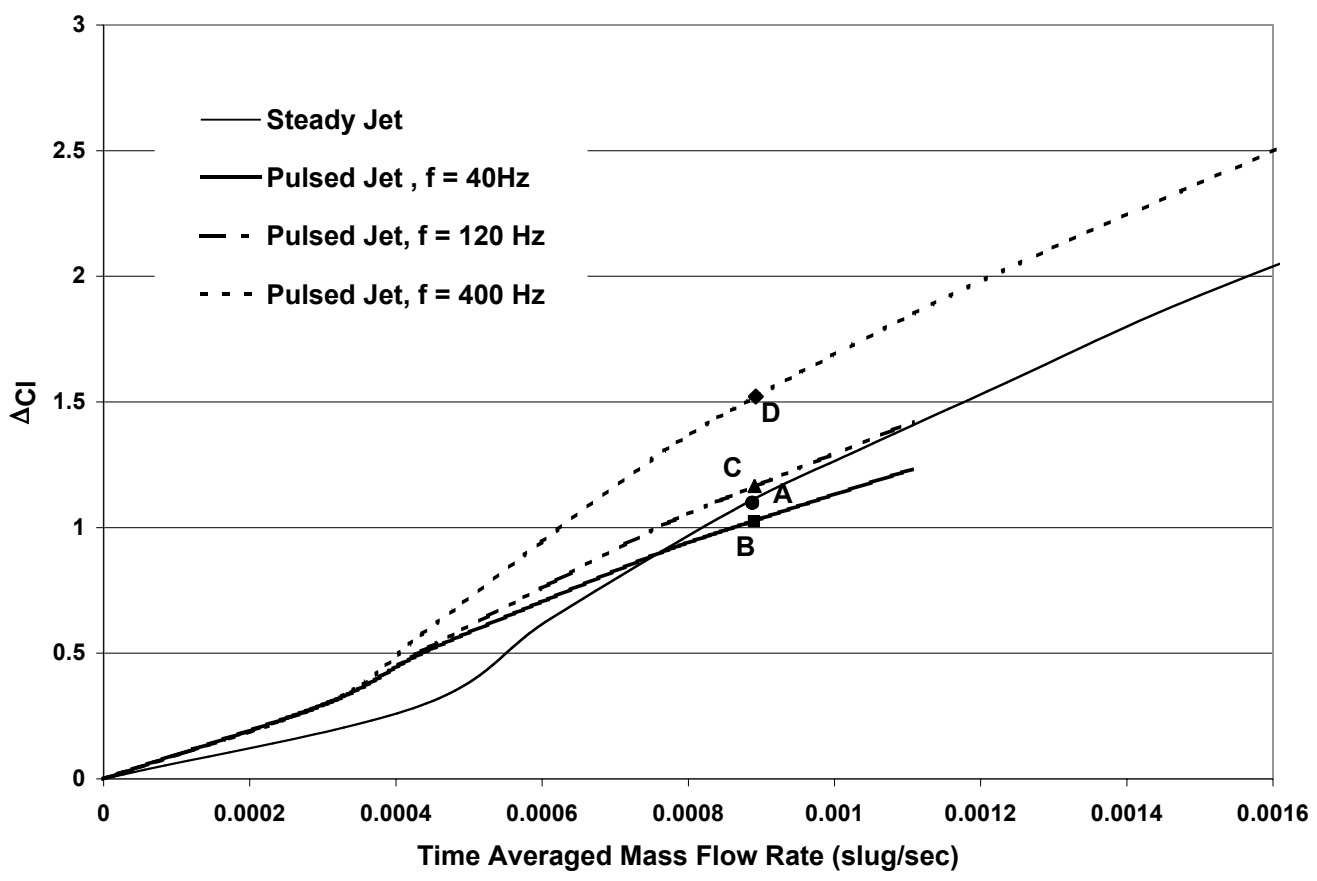

Figure 14 Incremental Lift Coefficient vs. Time-averaged Mass Flow Rate 


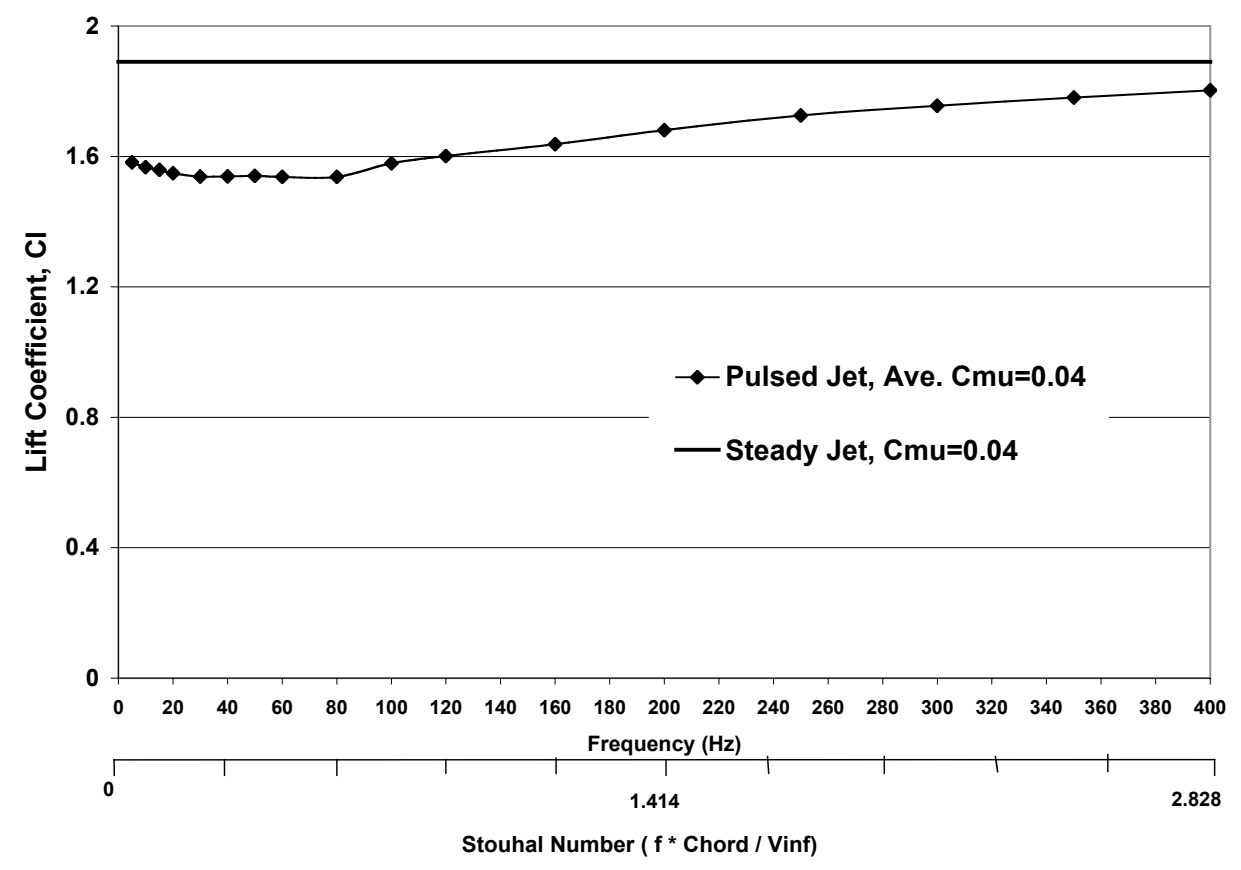

Figure 15 Time-averaged Lift Coefficient vs. Frequency \& Strouhal Number

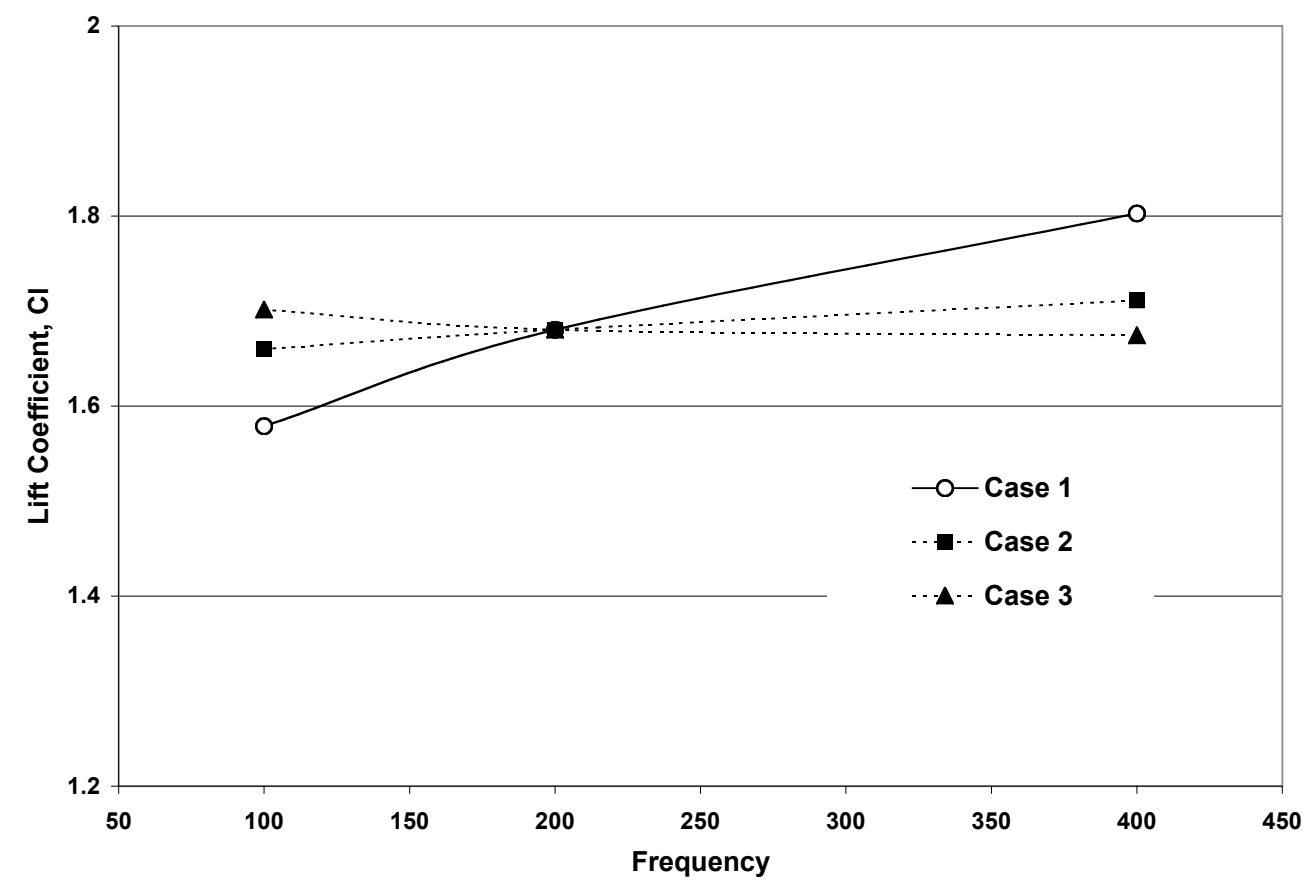

Figure 16 Time-averaged Lift Coefficient vs. Frequency

(Case 1. Strouhal number was not fixed; $U_{\infty}$ and $L_{\text {ref }}$ were fixed) (Case 2. Strouhal number and $L_{\text {ref }}$ were fixed; $U_{\infty}$ was not fixed) (Case 3. Strouhal number and $U_{\infty}$ were fixed; $L_{\text {ref }}$ was not fixed) 
Table 1 Computed Time-averaged Lift Coefficient for the Case where $U_{\infty}$ and $L_{r e f}$ are fixed, and the Strouhal number is varied by varying with the frequency

\begin{tabular}{|c|c|c|c|}
\hline & Baseline & Half Frequency & Double Frequency \\
\hline Frequency $(\mathrm{Hz})$ & 200 & 100 & 400 \\
\hline $\begin{array}{c}\text { Free-Stream Velocity } \\
\mathrm{U}_{\infty}(\mathrm{ft} / \mathrm{sec})\end{array}$ & 94.3 & 94.3 & 94.3 \\
\hline $\begin{array}{c}\text { Chord of the Airfoil } \\
\mathrm{L}_{\text {ref }} \text { (inch) }\end{array}$ & 8 & 8 & 8 \\
\hline $\begin{array}{c}\text { Strouhal Number } \\
\text { Computed Average Lift } \\
\text { Coefficient }\left(\mathrm{C}_{\mathrm{l}}\right)\end{array}$ & $\mathbf{1 . 4 1}$ & $\mathbf{0 . 7 0 5}$ & $\mathbf{2 . 8 2}$ \\
\hline
\end{tabular}

Table 2 Computed Time-averaged Lift Coefficient for the Case where Strouhal number and $L_{\text {ref }}$ fixed, and $U_{\infty}$ and the frequency are varied.

\begin{tabular}{|c|c|c|c|}
\hline & Baseline & Half Velocity & Double Velocity \\
\hline Frequency $(\mathrm{Hz})$ & 200 & 100 & 400 \\
\hline $\begin{array}{c}\text { Free-Stream Velocity } \\
\mathrm{U}_{\infty}(\mathrm{ft} / \mathrm{sec})\end{array}$ & 94.3 & 47.15 & 118.6 \\
\hline $\begin{array}{c}\text { Chord of the Airfoil } \\
\mathrm{L}_{\text {ref }} \text { (inch) }\end{array}$ & 8 & 8 & 8 \\
\hline $\begin{array}{c}\text { Strouhal Number } \\
\text { Computed Average Lift } \\
\text { Coefficient }\left(\mathrm{C}_{\mathrm{l}}\right)\end{array}$ & $\mathbf{1 . 4 1}$ & $\mathbf{1 . 4 1}$ & $\mathbf{1 . 4 1}$ \\
\hline
\end{tabular}

Table 3 Computed Time-averaged Lift Coefficient for the Case where Strouhal number and $U_{\infty}$ fixed, and $L_{\text {ref }}$ and frequency are varied.

\begin{tabular}{|c|c|c|c|}
\hline & Baseline & Double Chord & Half Chord \\
\hline Frequency $(\mathrm{Hz})$ & 200 & 100 & 400 \\
\hline $\begin{array}{c}\text { Free-Stream Velocity } \\
\mathrm{U}_{\infty}(\mathrm{ft} / \mathrm{sec})\end{array}$ & 94.3 & 94.3 & 94.3 \\
\hline $\begin{array}{c}\text { Chord of the Airfoil } \\
\mathrm{L}_{\text {ref }} \text { (inch) }\end{array}$ & 8 & 16 & 4 \\
\hline $\begin{array}{c}\text { Strouhal Number } \\
\text { Computed Average Lift } \\
\text { Coefficient }\left(\mathrm{C}_{\mathrm{I}}\right)\end{array}$ & $\mathbf{1 . 4 1}$ & $\mathbf{1 . 4 1}$ & $\mathbf{1 . 4 1}$ \\
\hline
\end{tabular}

